\title{
Erratum to: Analysis of agricultural drought characteristics through a two-dimensional copula
}

L. $\operatorname{Vergni}^{1} \cdot$ F. Todisco $^{1} \cdot$ F. Mannocchi ${ }^{1}$

Published online: 20 June 2015

(C) Springer Science+Business Media Dordrecht 2015

Erratum to: Water Resources Management

DOI 10.1007/s11269-015-0972-4

Unfortunately, the original publication of this paper contains some oversights in Figs. 3 and 5.

The online version of the original article can be found at http://dx.doi.org/10.1007/s11269-015-0972-4.

L. Vergni

lorenzo.vergni@unipg.it

1 Department of Agricultural, Food and Environmental Sciences, University of Perugia, Borgo XX, Giugno 74, 06121 Perugia, Italy 

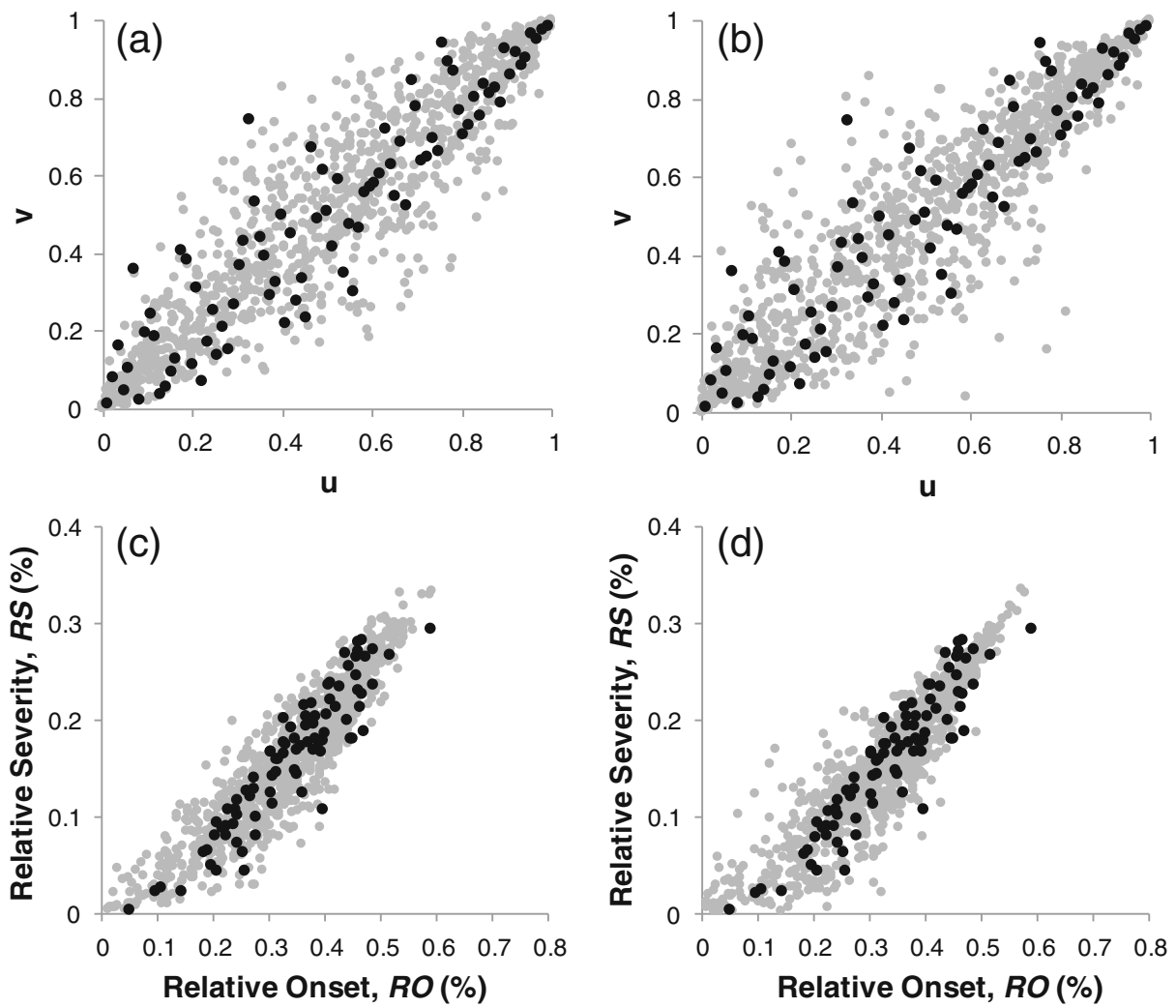

Fig. 3 One thousand random pairs $\left(u_{i}, v_{i}\right)$ - grey dots - simulated from a Student copula with parameters $\theta=0.92, \nu$ $=18 \mathbf{a}$ and a Gumbel copula with parameter $\theta=4.04 \mathbf{b}$ compared to pseudo-observations $\left(r_{i} /(n+1), s_{i} /(n+1)\right)$ derived from the observed samples of drought characteristics $R O$ and $R S$ (black dots); in $\mathbf{c}$ and $\mathbf{d}$ the same random pairs $\left(u_{i}, v_{i}\right)$ are transformed by the inverse truncated Gumbel distribution in the physical variables $\left(r o_{i}, r s_{i}\right)$ and compared with observed pairs of $R O$ and $R S$ (black dots). $R O$ is expressed as residual percentage of the growing season
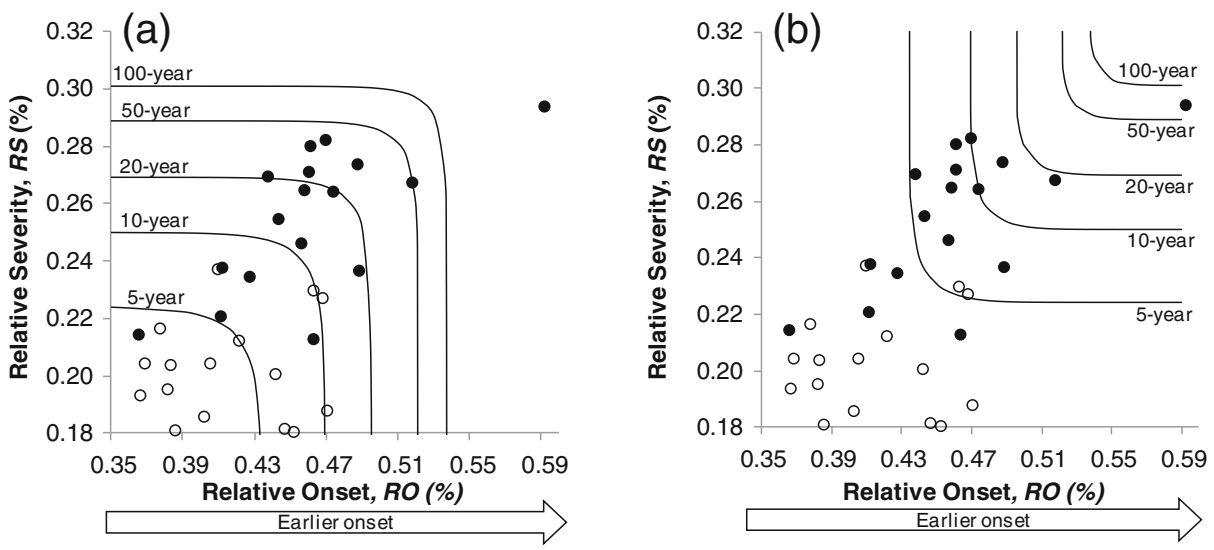

Fig. 5 Contourlines of joint return periods, $T R_{A N D}$, of $R O \geq r o$ and $R S \geq r s$ a and of joint return periods, $T R_{O R}$, of $R O \geq r o$ or $R S \geq r s \mathbf{b}$. Circles are the observed pairs $\left(r o_{i}, r s_{i}\right)$, the black-filled ones correspond to critical crop yields. $R O$ is expressed as residual percentage of the growing season 